\title{
On the sensitivity of a regional Arctic climate model to initial and boundary conditions
}

\author{
Annette Rinke*, Klaus Dethloff
}

\author{
Alfred Wegener Institute for Polar and M arine Research, Potsdam, Telegrafenberg A43, 14473 Potsdam, G ermany
}

\begin{abstract}
The sensitivity of Arctic atmospheric simulations to initial and boundary conditions was investigated with the high horizontal resolution regional climate model HIRHAM driven by observational data analyses at the lateral and lower boundaries. Investigation of the constraint of the synopticscale flow in the specific circumpolar Arctic domain showed that even though the same domain size as in mid-latitude RCM (regional climate model) simulations was used, a weaker constraint of the synoptic scales and a smaller predictability were obtained. A simple spectral analysis showed that only scales with wavelengths longer than $1000 \mathrm{~km}$ contribute to the higher root-mean-square difference. Due to the weaker lateral boundary control a pronounced sensitivity of the Arctic simulations to uncertainties in initial conditions was found. The changes in the monthly mean atmospheric structures due to internal processes were of the same order as those due to inaccurate physical parameterizations. Sensitivity experiments concerning changed sea ice thickness showed a substantial impact of the lower boundary conditions on the monthly mean atmospheric structures up to the middle troposphere.
\end{abstract}

KEY WORDS: Regional climate model evaluation - Initial and boundary conditions $\cdot$ HIRHAM $\cdot$ Arctic climate

\section{INTRODUCTION}

The concept of limited-area climate modeling has been sucessfully applied in the simulation of the Arctic climate at high spatial resolution with the western Arctic regional climate system model (RCM) ARCSyM (Walsh et al. 1993, Lynch et al. 1995, 1997) and the atmospheric RCM HIRHAM over the whole Arctic (Dethloff et al. 1996, Rinke et al. 1997). A RCM approach provides a powerful tool for improving the simulation of regional effects of the Arctic climate as a result of better resolved orography, nonlinear energy transfer and instability processes in the atmospheric motion spectrum. McGregor (1997) gives a short review of the basic methodology, recent simulations, and limitations of RCMs. To discuss the limitations of RCMs, sensitivity experiments aimed at evaluating the effects of different physical parameterizations, boundary conditions and initial conditions on the simulated climate are necessary for the purpose of understanding model biases and uncertainties. In the literature on

*E-mail: arinke@awi-potsdam.de
RCMs such tests appear to be very poorly discussed although some work has been done. Sass \& Christensen (1995) pointed out that a fundamental question to be considered in the context of RCM simulations is concerned with how the strength of the interior solution is affected by the forcing from the boundaries and in what way the interior solution depends on the quality of the boundary fields. The influence of the lateral boundary forcing on RCM simulations over Europe has been considered by Giorgi \& M arinucci (1991), J ones et al. (1995), Cress et al. (1995) and M achenhauer et al. (1997), who showed that any systematic error in the driving fields is transmitted to the RCM. In the current paper the coupling of the nested RCM to the driving model is investigated in a very specific domain, that of the circumpolar Arctic. We assume that baroclinic perturbations are allowed to stay within the domain for much longer time periods than in typical RCM integrations over mid-latitude domains. We address the following question: How are the amount of lateral boundary control and and its associated error related to uncertainties in the initial conditions in this specific domain? 


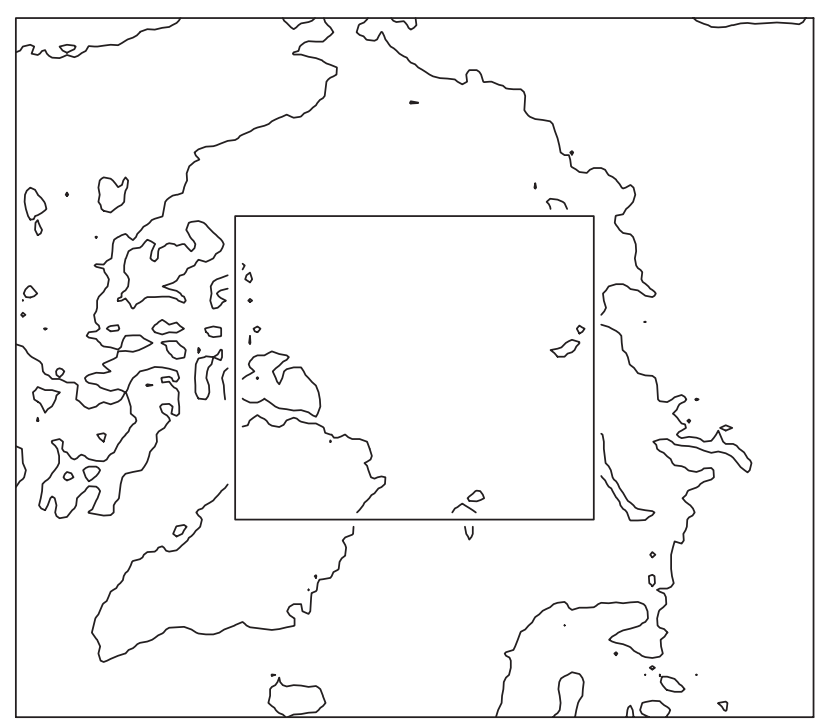

Fig. 1. Domains used for regional model simulations over the Arctic. The whole $110 \times 100$ domain (domain ARC) is normally used, but the inner small $50 \times 44$ domain (domain $A O$ ) is used here for a sensitivity study

Of course, the RCM solution depends on the quality of the RCM. Besides the dynamic part (numerical discretization, resolution, horizontal diffusion, time integration scheme, etc.), this quality relies mainly upon the physical parameterizations. The improvement of Arctic RCM simulations due to more advanced physical parameterizations was discussed, e.g., in Lynch et al. (1995), A begg et al. (1997), Pinto et al. (1997), and Rinke et al. (1997).

A short model description is given in Section 2. In Section 3 the constraint of the synoptic-scale flow due to the lateral forcing is discussed in the specific domain used (circumpolar Arctic). The influences of changed initial states and sea ice thickness on J anuary and J uly RCM simulations are discussed in Sections 4 and 5. Finally, Section 6 summarizes the main conclusions.

\section{MODEL SET-UP}

The atmospheric RCM HIRHAM (Christensen et al. 1996), which contains the physical parameterization package of the general circulation model (GCM) ECHAM (DKRZ 1992, Roeckner et al. 1996), was applied on a model area covering the whole Arctic north of about $65^{\circ} \mathrm{N}$. The model's horizontal grid is based on a rotated latitude/longitude grid with a rotated North Pole at $\left(0^{\circ} \mathrm{N}, 0^{\circ} \mathrm{E}\right)$ and a horizontal resolution of $0.5^{\circ}$ in rotated latitude and longitude. We use $110 \times 100$ gridpoints (domain ARC) in the horizontal and 19 vertical levels from the surface up to $10 \mathrm{hPa}$. A detailed description of the dynamical and physical properties of the model has been given in Dethloff et al. (1996). The model is forced at the lateral boundaries by the European Centre for Medium-Range Weather Forecasts (ECM WF) analyses updated every $6 \mathrm{~h}$. The information from the lateral boundaries is transferred to the model by a relaxation procedure for the prognostic fields using a 10 gridpoint wide boundary zone. At the lower boundary the model is forced by ECM WF analysed sea surface temperature (SST) and sea ice fraction, updated daily. In Section 3 and 4 an alternative circumpolar RCM domain with $50 \times 44$ gridpoints (domain $\mathrm{AO}$ ) is considered, containing only the central Arctic Ocean north of about $73^{\circ} \mathrm{N}$ (see Fig. 1).

\section{CONSTRAINT OF THE SYNOPTIC-SCALE FLOW}

The starting point of nested models is that lateral boundary conditions (BC) are set to constrain the RCM simulation to the same synoptic conditions as those provided by the nesting data, so that the continual boundary forcing is designed to keep the large-scale circulation features similar to those of the driving model (here ECMWF analyses). To sort out whether the RCM runs are coupled to or decoupled from the lateral BC, one has to make sure that long-term biases do not accumulate in the interior of the domain. Therefore, we calculated the root-mean-square ( $r m s$ ) difference between daily simulated and observed $500 \mathrm{hPa}$ geopotential heights, averaged over the whole domain excluding the boundary zone. In Fig. 2 the bold line shows the time trace of this rms difference for a yearly integration over the year 1990 using ECHAM 3 physics measuring the day-by-day mismatch of the simulated and analysed fields. The rms difference increases quickly from zero at the beginning of the integration to a maximum of $130 \mathrm{gpm}$ around Day 10 before substantially reducing to lower values and fluctuating around a mean asymptotic value of about 70 to $80 \mathrm{gpm}$. Singlemonth integrations using the model version with an improved physical package (HIRHAM with ECHAM 4 physical parametrizations) reduce the rms difference by about $40 \mathrm{gpm}$ (not shown here). Fig. 2 shows that the error curve does not grow with time. It is accepted that this quasi-equilibration of model error is explained by the comparable and counteracting influence of physically induced internal error growth and lateral boundary induced externally forced error reduction (e.g. Giorgi 1990, Luethi et al. 1996). Anthes (1986) introduced this as the extended predictability of nested models. Giorgi (1990) showed that this equilibrium depends on the strength of the advection from the boundaries and the strength of the local forcing. The results in Fig. 2 are partly comparable with RCM inte- 


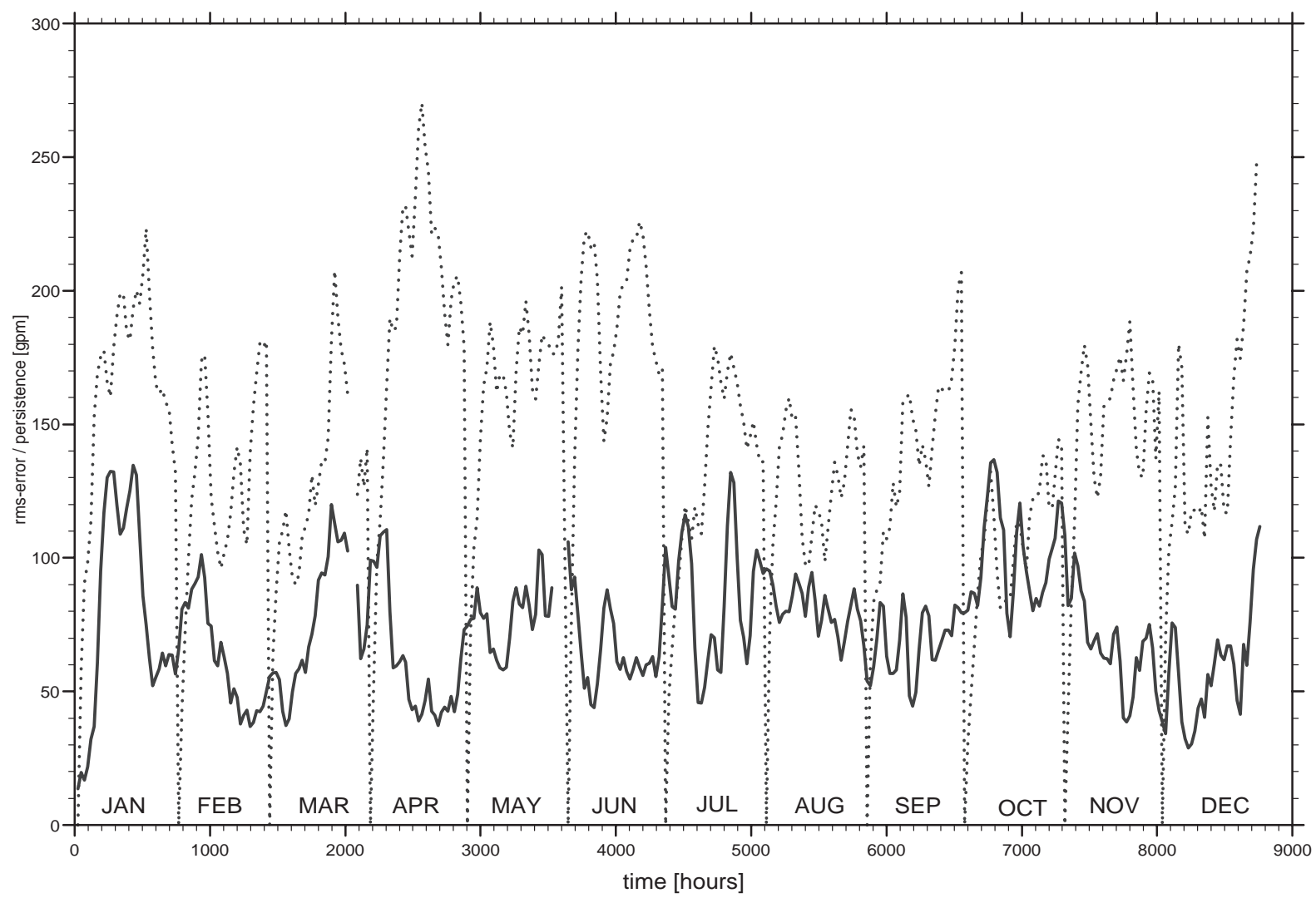

Fig. 2. Domain-averaged rms difference between the simulated and analysed $500 \mathrm{hPa}$ geopotential height for the year 1990 (bold line) and persistence of the analysed $500 \mathrm{hPa}$ height for each month of the year (dotted line)

grations of other authors. Bhaskaran et al. (1996) found in their seasonal simulation of the Indian summer monsoon a quick increase in the geopotential rms difference, averaged over 700 and $850 \mathrm{hPa}$, to a maximum around Day 20 and then a subsequently reduction to about the half rms value. Luethi et al. (1996) found in their monthly simulation of the European circulation a mean asymptotic value of 20 to $30 \mathrm{gpm}$ for J anuary 1993 and 40 to $50 \mathrm{gpm}$ for the $500 \mathrm{hPa}$ geopotential rms difference for J uly 1993.

Fig. 2 additionally presents the persistence of the analysed $500 \mathrm{hPa}$ height relative to the initial state (dotted line). It was calculated for each month separately and relative to the corresponding initial state of the month. The comparison of both lines in Fig. 2 shows that for most of the months (A pril-J une, September and November-December, 1990) about $70 \%$ of the observed deviation from persistence is correctly simulated by the model, while for J anuary-M arch and July-August 1990 the corresponding value is only about 40 to $50 \%$.

To demonstrate additionally that the solutions do not diverge from the forcing $B C$ more clearly by projecting the dynamical fields at any time level on a set of empir- ical orthogonal functions (EOFs), such an EOF analysis has been applied on the daily $500 \mathrm{hPa}$ heights. The time series of amplitudes of the ith EOF are called the ith principal component $(\mathrm{PCi})$ of the time series. The EOFs and PCs were normalized by the square root and the reciprocal of the square root of the eigenvalues, respectively (von Storch 1995). In this normalization the PCs have variance $=1$ and the relative strength of the signal is in the EOF patterns. Fig. 3 shows the time series of PC1 (the amplitudes of the leading EOF) for the simulated and analysed fields for J anuary and J uly of the yearly run of 1990. For J anuary EOF1 represents about $32 \%$ and for J uly about $40 \%$ of the total variance of the $500 \mathrm{hPa}$ height field. The simulated and observed curves are highly correlated, with correlation coefficients of more than 0.9.

In summary, these results reflect an adequate BC nesting, but in comparison to the RCM simulations for mid-latitude domains our results for the circumpolar Arctic area are different in several aspects. The asymptotic value of the error curve is higher than for RCM integrations over Europe and from time to time outbursts occur. This could be connected with the computational domain size used and/or the particular geo- 

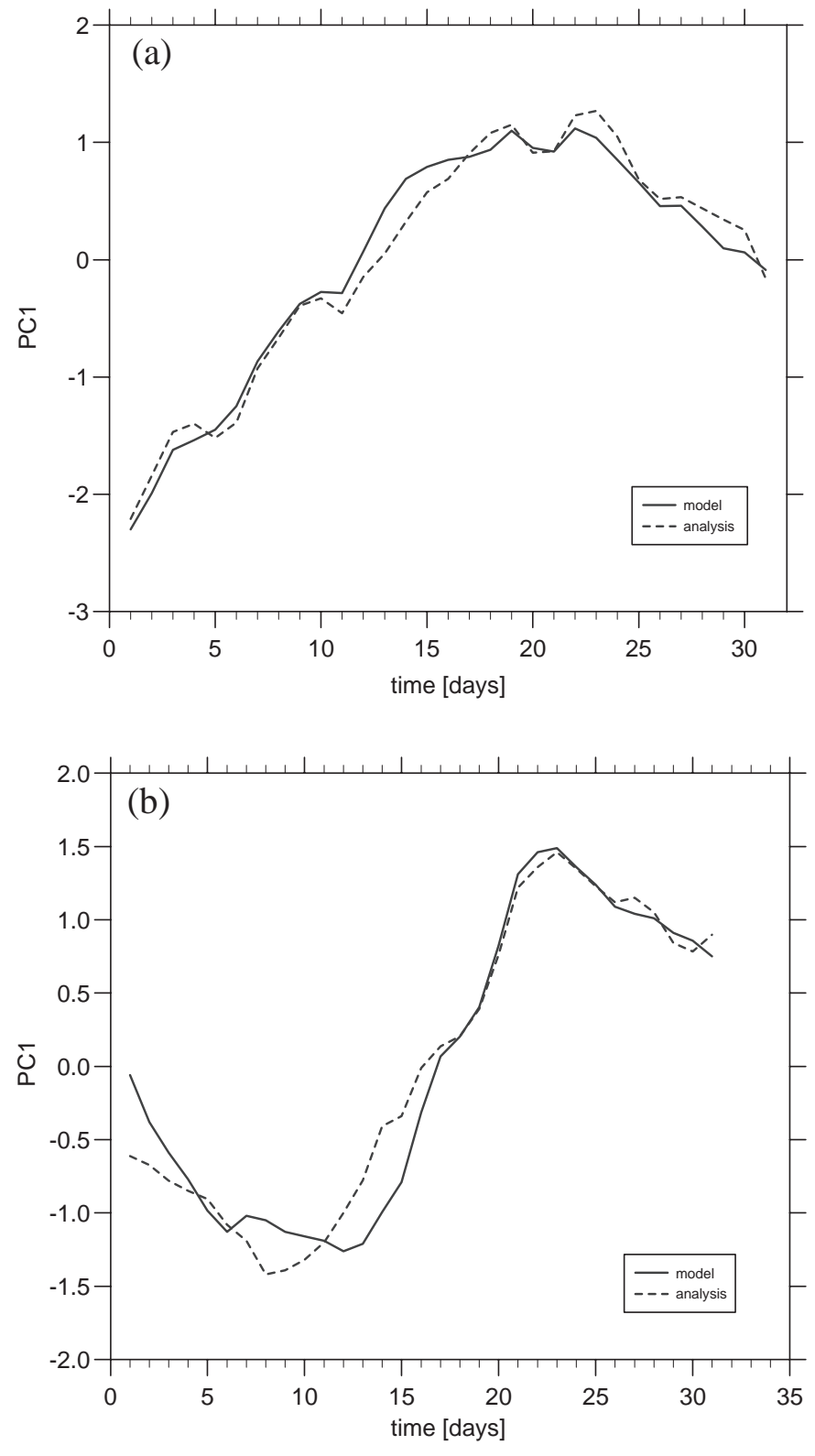

Fig. 3. Time series of $\mathrm{PC} 1$ (the first principal component) of the first EOF (empirical orthogonal function) of the simulated (bold line) and analysed (dashed line) daily $500 \mathrm{hPa}$ heights for (a) J anuary and (b) J uly 1990

graphical region. We used an integration area of $110 \times$ 100 gridpoints, corresponding to a size of about 23 million $\mathrm{km}^{2}$, which is also often used for RCM simulations over Europe (Cress et al. 1995, J ones et al. 1995, Luethi et al. 1996, Machenhauer et al. 1996, 1998) and over the United States (Seth \& Giorgi 1998). Vukicevic \& Errico (1990) found a critical size of 20 million $\mathrm{km}^{2}$, in the sense that for smaller domains initial perturbations are damped. Vukicevic \& Errico (1990) showed that in RCM domains of sufficient size the baroclinic waves can diverge from their counterparts in the driving model and then interact with the long waves of the lateral BC and modify them. J ones et al. (1995) found that RCM simulations over Europe are sensitive to the domain size. Similar results obtained by Cress et al. (1995), but they pointed out that most of the differences between the simulated climates using different sizes are rather small. For RCMs in mid-latitudes the main advantage is the prevailing strong zonal circulation due to which the error growth is mitigated by a fast propagation of true information from the lateral boundaries into, and of model-generated errors out of, the model domain. In the tropics, for example, the weather patterns move more slowly, meaning that the boundary information flashes in and out much more slowly, which could result in a somewhat independent development from the forcing model. The same problems occur over the European area during summertime simulations with a weaker zonal circulation (Luethi et al. 1996) and for very large domains (J ones et al. 1995). What is the situation like over the circumpolar Arctic integration area? One of the main characteristics of the Arctic dynamics is the polar vortex with its tropospheric extension during winter. It acts as a barrier to transient eddies in the troposphere but these weather systems are the most important mechanism for horizontal heat transport. Atmospheric waves can stay in the circumpolar domain for a long period.

To separate the horizontal scales which contribute to the error growth in Fig. 2 we applied a low-pass gridpoint filter by calculating running means over gridboxes of different size on the simulated daily J anuary and J uly $500 \mathrm{hPa}$ heights. We used gridboxes of $10 \times$ $10,20 \times 20$, and $40 \times 40$ grids only representing waves longer than 1000, 2000, and $4000 \mathrm{~km}$, respectively. When calculating the differences between the unfiltered and filtered variables, we obtained the components containing only the scales with shorter wavelengths. In Fig. 4 the black lines show the J anuary 500 $\mathrm{hPa}$ height rms errors for the ARC domain. The solid line shows the whole component (which corresponds to the curve from Fig. 2, but is here for single-month simulations using ECHAM 4 physics). The dashed line shows the filtered component containing only the scales with wavelengths shorter than $1000 \mathrm{~km}$. The figure indicates that only horizontal scales with wavelengths longer than $1000 \mathrm{~km}$ contribute to the outbursts and higher asymptotic value of the rms difference. The same holds for the July case (not shown here). The large scales of the error suggest that baroclinic instability may play a significant role in this error behaviour as discussed in Vukicevic \& Errico (1990). The specific domain considered (circumpolar Arctic) al lows baroclinic perturbation to stay within the domain for much longer time periods than in typical 
RCM integrations over mid-latitude domains and to react with the internal dynamics. For this reason the predictability of the large-scale patterns for such an Arctic domain is substantially smaller than for mid-latitude domains of equal size.

Let us look at the error behaviour using a smaller domain size over the circumpolar Arctic area. For this sensitivity study we choose a domain with $50 \times 44$ gridpoints (domain $\mathrm{AO}$ containing only the central Arctic Ocean north of about $73^{\circ} \mathrm{N}$, described by the inner area in Fig. 1), and with the same grid spacing of $50 \mathrm{~km}$. In Fig. 4 the grey lines show the corresponding $500 \mathrm{hPa}$ height unfiltered and filtered rms differences for the AO area for J anuary 1990. The asymptotic rms error is now about $15 \mathrm{gpm}$ and on the same order of magnitude as known from larger RCMs in mid-latitudes. The large scales cannot react significantly to the internal dynamics because in that very small domain they are now strongly constrained by the boundaries. The correlation coefficient between the time series of PC1 of simulated and analysed $500 \mathrm{hPa}$ height is 0.99 .

The results in this section demonstrate that RCM runs over the circumpolar Arctic integration area are not decoupled from the lateral BC. Even though the same domain size is used as that widely chosen for

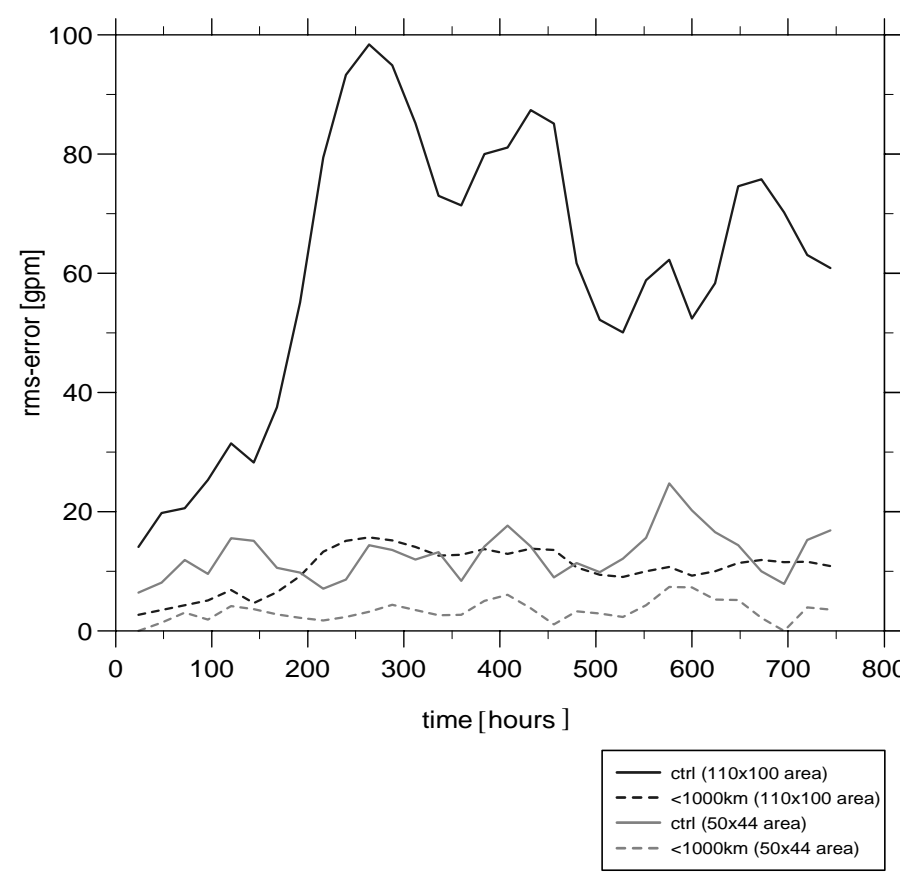

Fig. 4. Domain-averaged rms difference between the simulated and analysed $500 \mathrm{hPa}$ geopotential height for J anuary 1990. Black lines are for the ARC domain and grey lines are for the AO domain. Solid lines: unfiltered difference; dashed lines: only the rms components with wavelengths shorter than $1000 \mathrm{~km}$ mid-latitude RCM simulations, a different constraint of the synoptic scales and a smaller predictability of the large scales were observed. More precisely, the RCM is more weakly coupled to the lateral BC compared with mid-latitude RCMs. A spectral analysis shows that only the synoptic-scale disturbances with wavelengths longer than $1000 \mathrm{~km}$ contribute to the outbursts and the higher rms difference. To alleviate the problem of weak coupling Laprise (pers. comm. 1999) suggested the replacement of the lateral BC nesting strategy with a nudging of the long waves in the RCM with those from the nesting data using data assimilation. Another way would be a 2-way nesting method where one would allow the RCM to diverge from the driving model on larger scales hoping that this would yield better results or a model with a variable-resolution grid.

\section{INFLUENCE OF THE INITIAL STATE ON THE SIMULATION}

To detect expected anthropogenic signals in polar regions as a result of increased greenhouse gas concentrations, improved knowledge of the influence of internal processes on atmospheric structures is needed. Following Hasselmann (1976) climate time scale variability can be produced by random weather time scale forcing. In this section the internally generated climate variability is investigated by computing the monthly mean structures for different initial states for the Arctic in a RCM .

Rabier et al. (1996) pointed out that the experience with data assimilation and forecast experiments at the ECM WF suggests that the largest forecast errors more often arise from errors in the initial conditions than from those in the model formulation. In contrast to the behaviour of global models, Anthes et al. (1989) found that the lateral BC exert a much stronger control over the error growth than the initial conditions and the use of different model physical parameterizations. For a mesoscale model he showed that at least in some cases (A nthes 1986) small differences in the initial conditions do not grow over a $72 \mathrm{~h}$ period if the lateral BC are the same, meaning there is no significant transfer of initial error energy from the smallest scales to the larger scales. He suggested that a weaker large-scale forcing leads to a stronger sensitivity with respect to uncertainties in the initial conditions. We analyze this problem for the Arctic domain by comparing the sensitivities of the ARC and AO domains.

Since the initial state of the atmosphere contains uncertainties due to the coarse observational network, a complete weather prediction should be formulated in terms of a probability distribution of forecast states. 
(a)

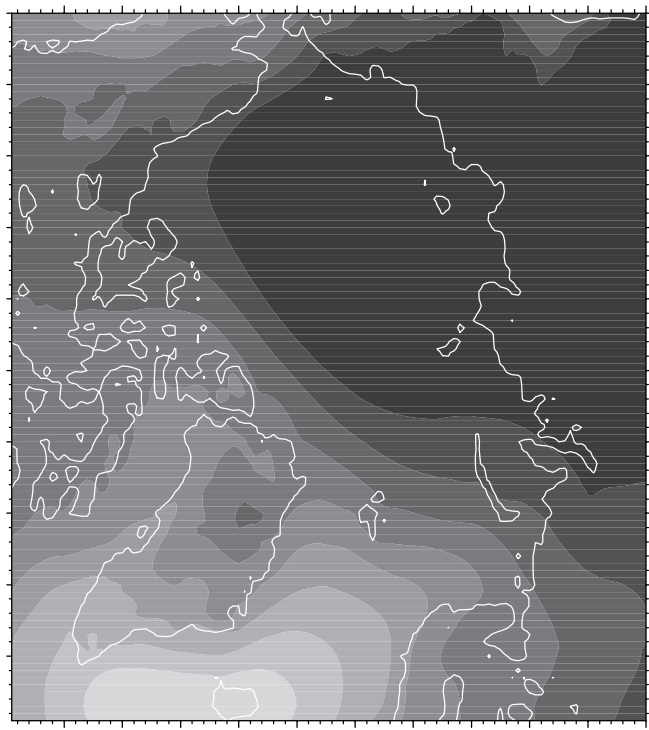

(b)

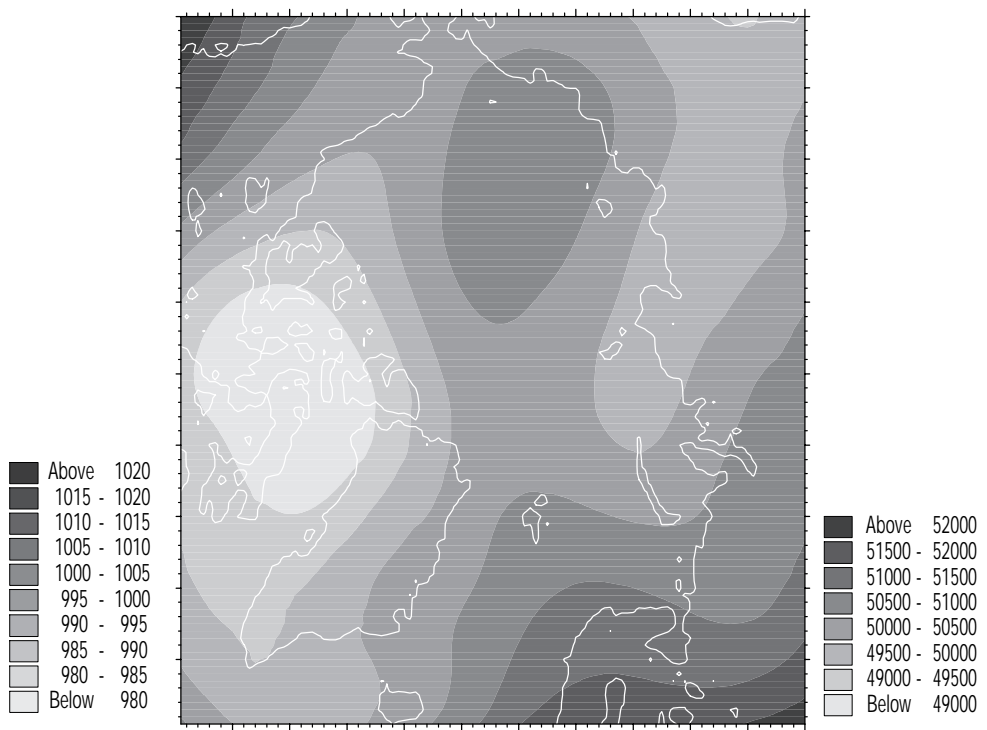

Fig. 5. Geographical distribution of monthly mean (a) sea level pressure in hPa and (b) 500 hPa geopotential in $\mathrm{m}^{2} \mathrm{~s}^{-2}$ for the J anuary ensemble

Ensemble prediction is a practical means of estimating this probability distribution for the medium range, where error evolution becomes nonlinear (M olteni et al. 1996). The ensemble technique, the integration of a numerical model from a variety of initial conditions, has been applied sucessfully in weather forecasting and seasonal climate prediction (Toth \& Kalnay 1993, Molteni et al. 1996, to name but two). The ensemble method adopted here for a RCM is an alternative approach to multiple-month RCM simulations as carried out for many geographical regions. An overview of these simulations is given by M CGregor (1997).

The sensitivity experiments described here, using the ensemble method, investigate the influence of inaccurate initial conditions on the monthly mean model structures for the winter month J anuary 1990 and the summer month J uly 1990 . Four simulations for each of these 2 months were carried out in the following way: All J anuary/J uly ensemble members start at 00:00 h UTC on J anuary/J uly 1 , but with initial conditions from J anuary/J uly 1 (control run or run aw), 2, 3, and 4 (runs aw2, aw3, aw4) at 00:00 h UTC. After initialization each run uses the same lateral and lower $B C$, so any differences between these runs occur as a result of changed instability processes as a consequence of changes in the initial states. Figs. $5 \& 6$ show the ensemble means of SLP (sea level presure) and $500 \mathrm{hPa}$ geopotential for J anuary and J uly, respectively; the ensemble means were computed as arithmetic averages of the 4 corresponding monthly means. Figs. $7 \& 8$ show the calculated ensemble standard deviations of SLP and $500 \mathrm{hPa}$ geopotential for the J anuary and July ensembles, respectively. They have been calculated from the differences of the ensemble mean and the monthly means of the aw, aw2, aw3, aw4 runs. These standard deviations show the representativeness of the ensemble mean in the model region or the internal mean model variability. It is obvious that as a result of the same lateral ECM WF boundary forcing in each of the 4 experiments in the 10 gridpoint wide boundary zone the standard deviations are very small. Fig. 7 shows that during J anuary the maximum standard deviations of the SLP and $500 \mathrm{hPa}$ geopotential occur in the Barents Sea, with values of up to $4 \mathrm{hPa}$ and $400 \mathrm{~m}^{2} \mathrm{~s}^{-2}$. Over the same region Dethloff et al. (1996) computed the maximum negative model bias (difference 'model minus ECMWF analyses') of SLP and $500 \mathrm{hPa}$ geopotential with the same order of magnitude. The investigation of HIRHAM 's interannual behaviour based on the simulations of $11 \mathrm{~J}$ anuary of 1985 to 1995 in Rinke et al. (1999) showed that the model develops a systematic error in the $500 \mathrm{hPa}$ geopotential over the Barents Sea and central Arctic Ocean of up to $300 \mathrm{~m}^{2} \mathrm{~s}^{-2}$. These differences are connected with errors due to uncertainties in the initial conditions, errors in the data and errors in the physical model parameterizations used. Fig. 8 illustrates that during July the standard deviations of the SLP and $500 \mathrm{hPa}$ geopotential show a 2-wave pattern, with maximum values over the eastern and western Arctic and maximum values similar to those in J anuary. The regions of maximum standard deviation are again 
(a)

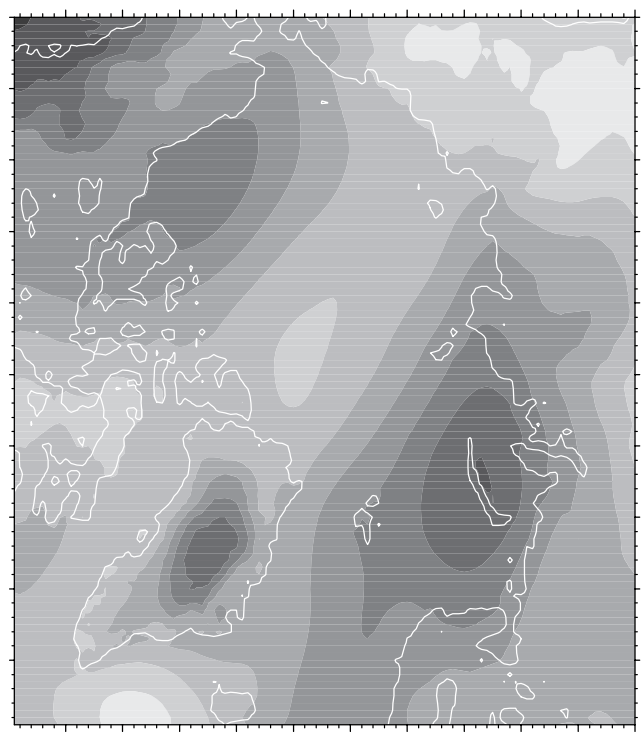

(b)

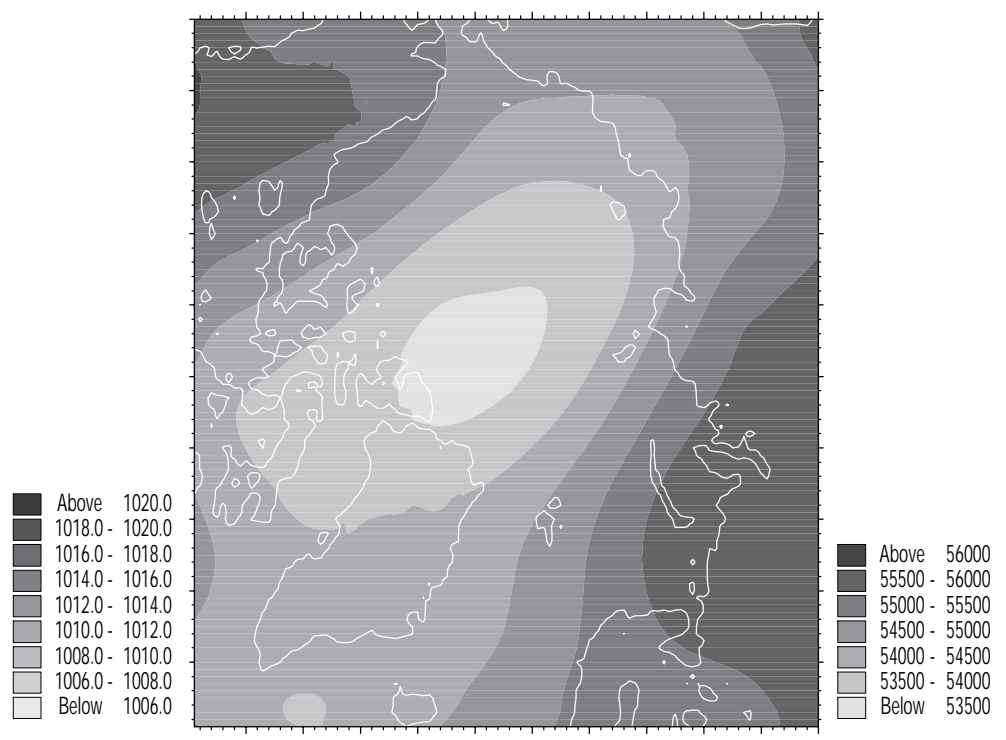

Fig. 6. Geographical distribution of monthly mean (a) sea level pressure in $\mathrm{hPa}$ and (b) $500 \mathrm{hPa}$ geopotential in $\mathrm{m}^{2} \mathrm{~s}^{-2}$ for the J uly ensemble

(a)

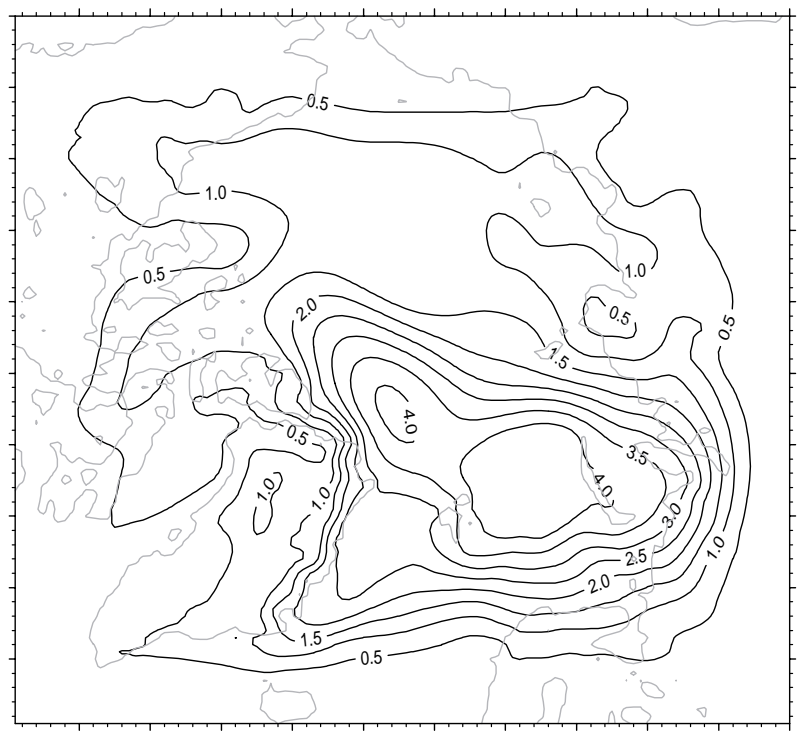

(b)

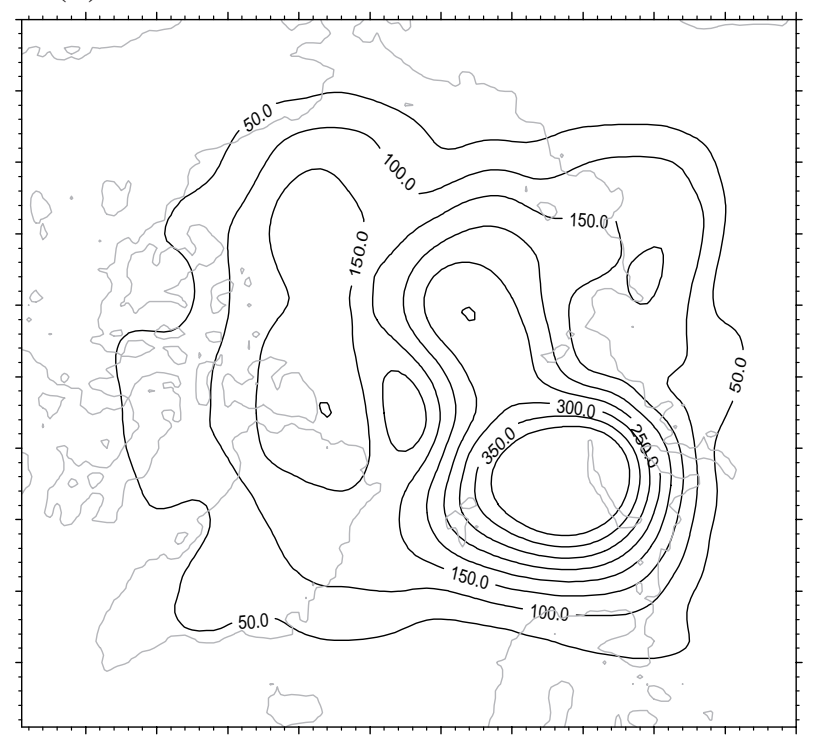

Fig. 7. Geographical distribution of the ensemble standard deviation of (a) sea level pressure in hPa and (b) $500 \mathrm{hPa}$ geopotential in $\mathrm{m}^{2} \mathrm{~s}^{-2}$ for the $\mathrm{J}$ anuary ensemble

identical with those where the model underestimates the SLP in comparison with ECM WF analyses.

The presented ensemble standard deviations of the runs with different initial states are of the same order as the model bias 'model minus analyses'. This means that the range of the internally generated noise as a result of inaccurate initial data is of the same order as the model bias due to incorrect parameterizations. By evaluating the dispersion of the simulations as a result of different initial states, here described by the standard deviation, a measure of the uncertainty of RCM simulations over the Arctic was obtained. The uncertainty in the initial conditions, which in the Arctic is largely due to sparse data, builds an upper limit for improvements of the bias of any RCM. The consequence for climatic change experiments in polar 
(a)

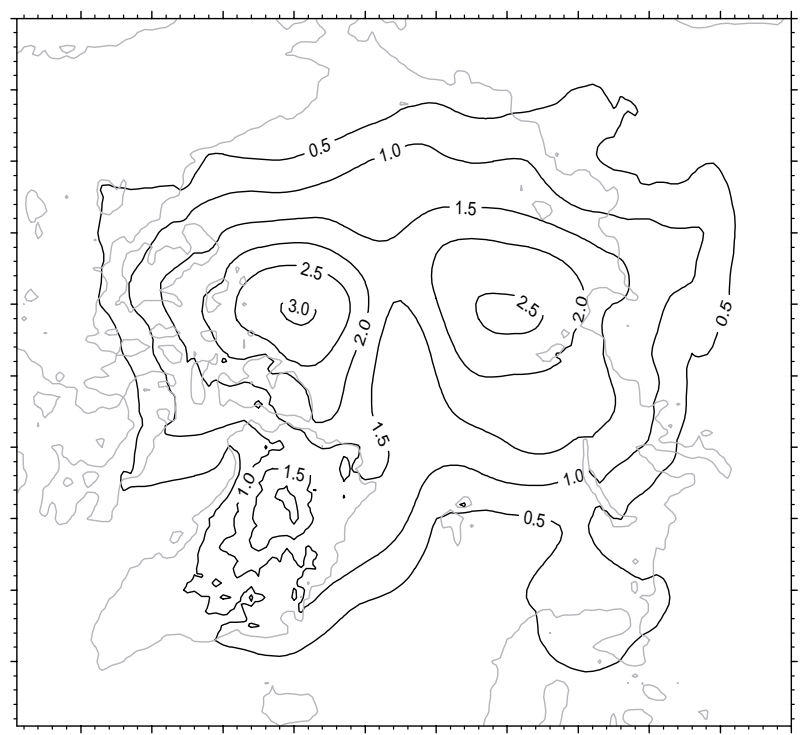

(b)

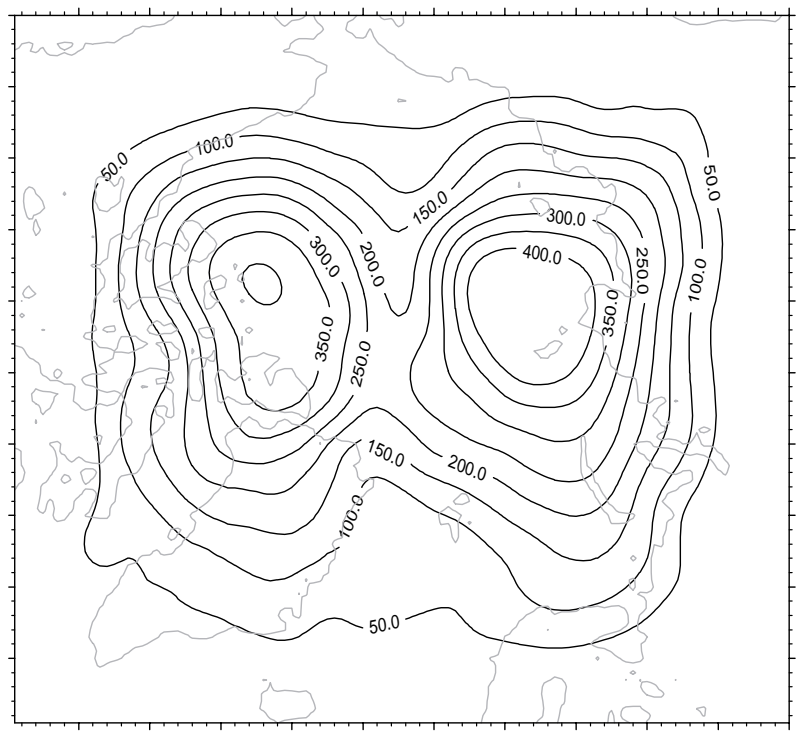

Fig. 8. Geographical distribution of the ensemble standard deviation of (a) sea level pressure in hPa and (b) $500 \mathrm{hPa}$ geopotential in $\mathrm{m}^{2} \mathrm{~s}^{-2}$ for the $\mathrm{J}$ uly ensemble

regions is that only regions where the standard deviation is small enough to allow the detection of an anthropogenic signal should be selected.

Fig. 9 shows time series of daily SLP and, 500 and 70 hPa geopotential for J uly at the gridpoint $(50,70)$ over the Arctic Ocean for 4 runs with different initial values. Even if the initial values differ only slightly from each other, the curves separate with time, resulting in monthly mean differences of up to $4 \mathrm{hPa}$ in SLP. Simulations starting from different initial states diverge from each other as a result of the development of nonlinear atmospheric instabilities. To demonstrate this divergence of the solutions more clearly by projecting the dynamical fields at any time level on an set of EOFs, such an EOF analysis was applied to the daily $500 \mathrm{hPa}$ heights. Fig. 10a shows the time series of PC1 of the $500 \mathrm{hPa}$ height field for the runs aw to aw4 for J uly 1990. EOF1 represents about $40 \%$ of the total variance of the $500 \mathrm{hPa}$ height field. The calculated correlation coefficients between these time series are larger than 0.9 .

In summary, in our RCM simulations we obtained a pronounced sensitivity to uncertainties in the initial conditions. This result is in contrast to the result of other authors (see, e.g., a survey in Paegle et al. 1997). We conclude that the weaker large-scale boundary forcing in our ARC domain discussed in Section 3 leads to the stronger sensitivity. We repeated the J uly 1990 integrations using the different initial conditions aw, aw2, aw3 and aw4, but now using the smaller AO domain. Fig. 10b shows the time series of $\mathrm{PC} 1$ of the $500 \mathrm{hPa}$ geopotential height for these runs. The corre- lations between the 4 time series are quite strong, with correlation coefficients of 0.99 . There is practically no dependence on the initial value. Investigating the sensitivity to initial soil moisture, Seth \& Giorgi (1998) also found that according to the domain size the same model produces quite different sensitivities. The ensemble standard deviation for the $500 \mathrm{hPa}$ geopotential of the J uly ensemble is represented in Fig. 11 and shows a maximum of only $20 \mathrm{~m}^{2} \mathrm{~s}^{-2}$. A comparison of this figure with the corresponding deviation pattern in the ARC domain in Fig. 8b shows that the use of the smaller domain reduces the standard deviation by a whole order of magnitude. But, as for the ARC domain, the model bias 'model minus analyses' for the AO domain (not shown here) is of the same order of magnitude and about in the same place as the ensemble standard deviation. Consequently, for both domains the maximum internal model variability is co-located with the the maximum model bias. It should be concluded that it is difficult to compare single-month integration results with the observed state. This is what Christensen et al. (1997) referred to as actual time verification; they also give a discussion of the limitations of this verification technique.

Finally, we compare the averaged skill of the ensemble simulation with that of the single-month simulation. In Fig. 12 the time series of the domain-averaged rms differences have been plotted for the SLP during J uly 1990, calculated on the basis of the single-month control run (run aw) on the one hand, and on the other on the basis of the whole J uly ensemble (runs aw and aw2, aw3, aw4). What we know from ECM WF ensem- 

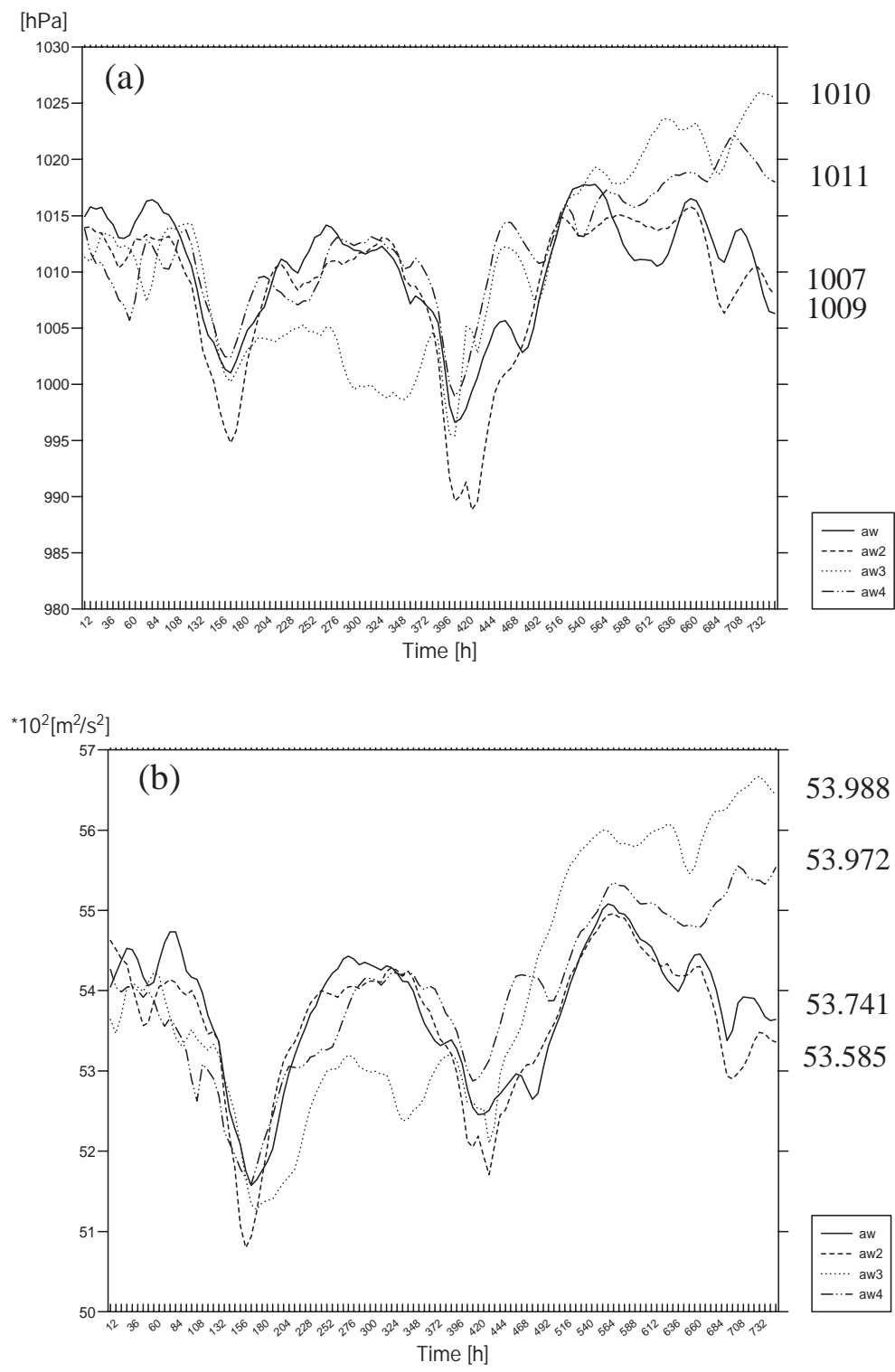

$* 10^{2}\left[\mathrm{~m}^{2} / \mathrm{s}^{2}\right]$

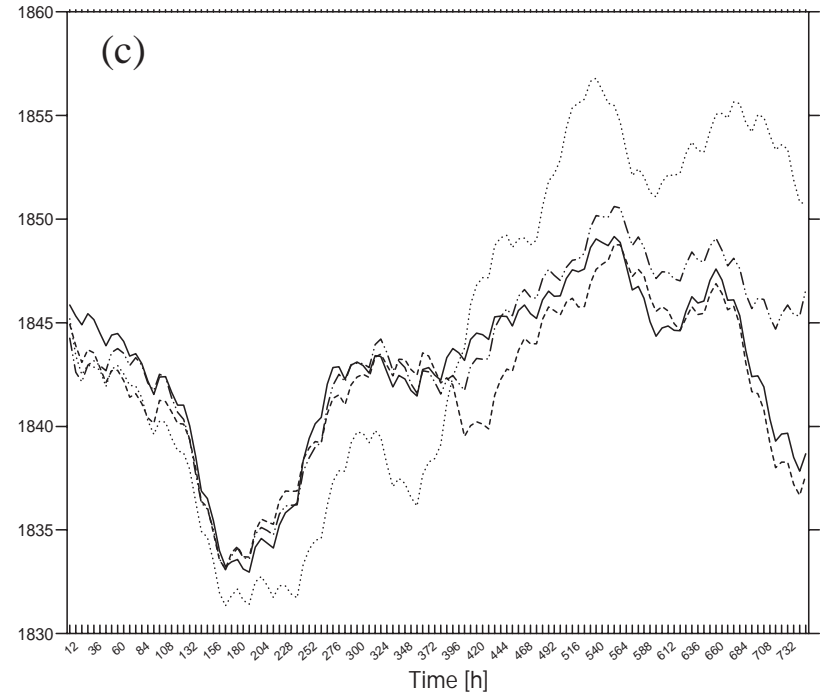

ble weather prediction systems is that the skill of the ensemble mean improves with respect to the control forecast after about Days 4 to 5 (Molteni et al. 1996). But what we see here in Fig. 12a for the ARC domain is that the improvement is evident only after Day 15. Considering the statistics of the whole-ensemble integrations, an improvement in the rms error occurs and the outbursts are weaker. The results for the $A O$ domain in Fig. 12b show again the very strong control of the error growth due to the lateral BC.

Trying to quantify the needed minimum number of realizations of a given month, we enlarged the J uly 1990 ensemble. As well as the 4 runs aw to aw4, we simulated 4 additional experiments called aw5, aw6, aw7 and aw8. All runs start also started at 00:00 h UTC on J uly 1 , but runs aw5, aw6 and aw 7 had initial conditions from J uly 1 at 12:00 h UTC, 06:00 h UTC and 18:00 h UTC, respectively. Run aw8 started with initial conditions from J uly 2, 06:00 h UTC. When we compare the rms differences of the different members ensembles in Fig. 12a, we see that no additional improvement occurs by using larger ensembles.

\section{INFLUENCE OF SEA ICE THICKNESS ON THE SIMULATION}

At the lower boundary we used a constant value of sea ice thickness for the whole Arctic integration area. Based on measurements, Flato \& Hibler (1995) showed that during J anuary the Arctic Ocean is covered with sea ice of a thickness of $4 \mathrm{~m}$, whereas on the Atlantic side the sea ice is much thinner, with a thickness between 1 and $2 \mathrm{~m}$. This section describes the sensitivity of the HIRHAM J anuary 1990 simulation to various sea ice thicknesses (1, 2 and $4 \mathrm{~m}$ ).

Fig. 13 shows the simulated monthly mean temperature at the lowest model level at approximately $30 \mathrm{~m}$ above

1842.68

1841.90

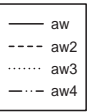

Fig. 9. Time series of daily (a) mean sea level pressure, (b) $500 \mathrm{hPa}$ geopotential and (c) $70 \mathrm{hPa}$ geopotential at the gridpoint $(50,70)$ for July 1990. At the right-hand side the monthly means are given 

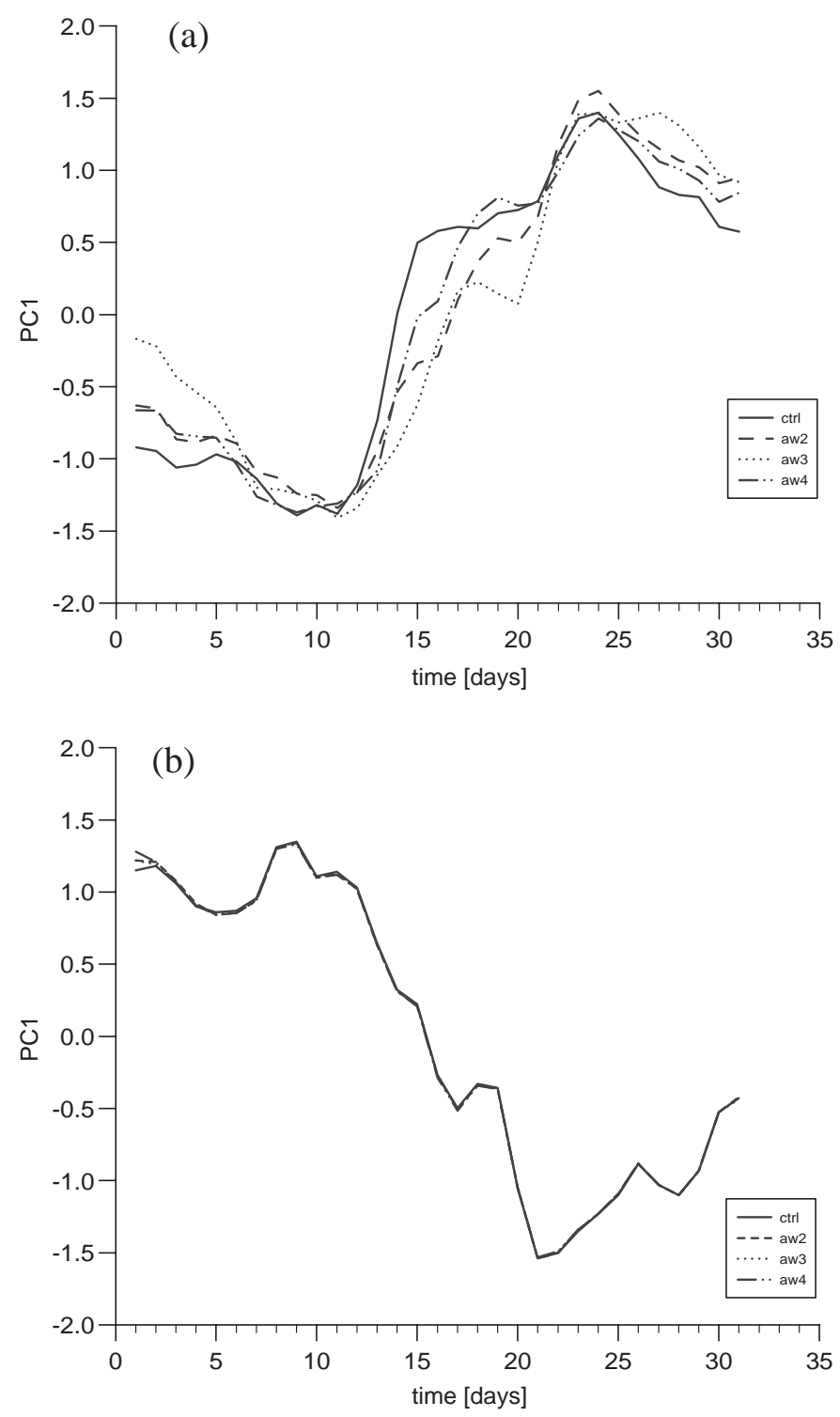

Fig. 10. Time series of $P C 1$ of the first EOF of the simulated daily $500 \mathrm{hPa}$ height for J uly 1990 runs with different initial values (runs aw, aw2, aw3 and aw4) for (a) domain ARC and (b) domain $\mathrm{AO}$

ground using $1 \mathrm{~m}$ sea ice thickness. In the difference map 'model minus analyses' (not shown here) the simulated temperature over the ice covered central Arctic Ocean is up to $10 \mathrm{~K}$ higher than the analysed temperature. This large difference is caused by sea ice in the model that is too thin. The ice-surface temperature is calculated from the energy balance at the ice surface, which is determined by the atmospheric energy flux (solar and thermal radiative fluxes, sensible and latent heat fluxes) and by the oceanic heat fluxes. The oceanic heat flux is parameterized in the model as being indirectly proportional to the ice thickness. Due to the chosen sea ice thickness of $1 \mathrm{~m}$ the heat flux from the underlying warmer ocean into the atmosphere is too high and induces a near-surface temperature in the model simulation that is too warm. An increase of the sea ice thickness changes the bias structure. Fig. 13b,c shows the changes in the monthly mean lowest model level temperature and SLP due to an increase of ice thickness from 1 to $4 \mathrm{~m}$. The increased sea ice thickness reduces the oceanic heat flux into the atmosphere, whereby the surface temperatures decrease up to $8 \mathrm{~K}$ and clearly reduce the warm temperature bias over the Arctic Ocean to $2 \mathrm{~K}$. In connection with the changed near surface temperature due to increased ice thickness, the SLP is reduced up to $5 \mathrm{hPa}$ over the Arctic Ocean. Fig. 13b,c shows further that for areas of single-year sea ice use of thinner ice thickness would be more suitable. Changes in sea ice thickness influence the thermal regime up to $500 \mathrm{hPa}$, but the greatest impact is visible in the near surface temperature, with changes of $4 \mathrm{~K}$, and in the surface fluxes.

To obtain a more realistic winter simulation, it seems necessary to distinguish between single-year and multiyear sea ice, i.e. to use at least regionally different sea ice thickness. Lynch et al. (1995) showed that the inclusion of sea ice dynamics has substantial impacts on the model results for winter and suggested the construction of a fully coupled atmosphere-ocean-sea-ice RCM over the Arctic. Such an approach is underway.

\section{SUM MARY}

To look at the very specific circumpolar Arctic domain used for RCM simulations, we addressed the issue of synoptic-scale constraint of the flow inside the RCM. It was shown that in this specific circumpolar Arctic domain the lateral boundary control is weaker compared to that in corresponding domain sizes in mid-latitude areas. The investigation showed a smaller predictability of large scales in the Arctic compared to mid-latitude RCMs. We showed that the predictability depends on both the domain size and the domain location. Even with perfect BC, RCMs may develop systematic errors in the simulation of the large-scale flow if the boundary forcing is weak. For such model configurations the value of single-month integrations to validate the model is weak. Seth \& Giorgi (1998) showed that larger domains are likely to be preferred for testing the sensitivity to internal model processes because the model solution is more free to respond to variations in internal parameters.

A simple spectral analysis showed that only horizontal scales with wavelengths longer than $1000 \mathrm{~km}$ contribute to the higher root mean square difference. The main sources of local error growth are associated 


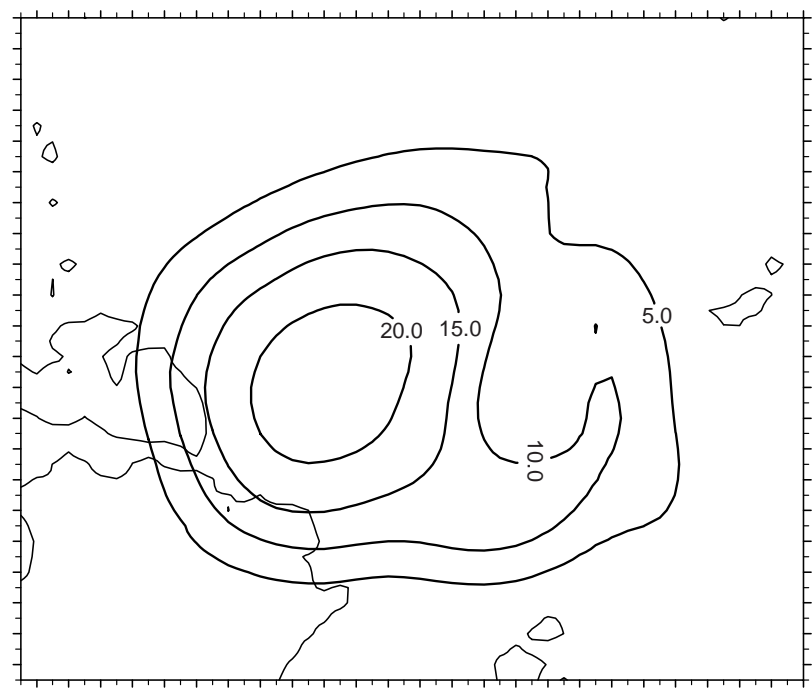

Fig. 11. Geographical distribution of the ensemble standard deviation of the $500 \mathrm{hPa}$ geopotential in $\mathrm{m}^{2} \mathrm{~s}^{-2}$ for the July ensemble using the smaller $\mathrm{AO}$ domain

rather with small uncertainties of the larger spatial scales than those of the smaller scales.

The condition that lateral BC are set to constrain the RCM simulation to the same synoptic conditions provided by the nesting data ensures that the RCM acts purely as a physically based nonlinear interpolator on the coarser nesting model (Goyette \& Laprise 1996). However, in the Arctic the observational data analyses used are mainly based on the ECMWF forecast model as a result of the coarse data. For this reason it is difficult to evaluate the differences between the simulated and the analysed fields, and it would be interesting to allow the RCM fields to diverge from the driving data on larger scales, hoping that this will yield better results. A 2-way nesting procedure or a global model with variable-resolution grid would provide a solution.

Due to the weaker lateral boundary control a more pronounced sensitivity to uncertainties in initial conditions is found in comparison to other mesoscale models, as discussed, e.g., in Paegle et al. (1997). The uncertainty in the initial conditions, which in Arctic regions as a result of coarse data is especially large, sets an upper limit for improvements of the bias of any RCM. The maxima of the standard deviations seem to be connected with the storm tracks in winter and summer and are strongly determined by baroclinic instability processes. The changes of the monthly mean atmospheric structures due to the changes of the internal processes are of the same order as the model bias due to inaccurate physical parameterizations. However, if the domain is small enough the dependence of the simulation on initial uncertainties is weak.
The influence of sea ice thickness at the lower boundary on the simulations is quite strong in the Arctic. Large fluxes of heat and moisture, particularly from leads and polynyas, shape the local and downstream circulation. The experiments described here underline the fact that in the Arctic region a well-suited description of the surface characteristics and planetary boundary layer physics is most important. An appropriate incorporation of the sea ice characteristics is crucial for a realistic simulation of the Arctic climate.
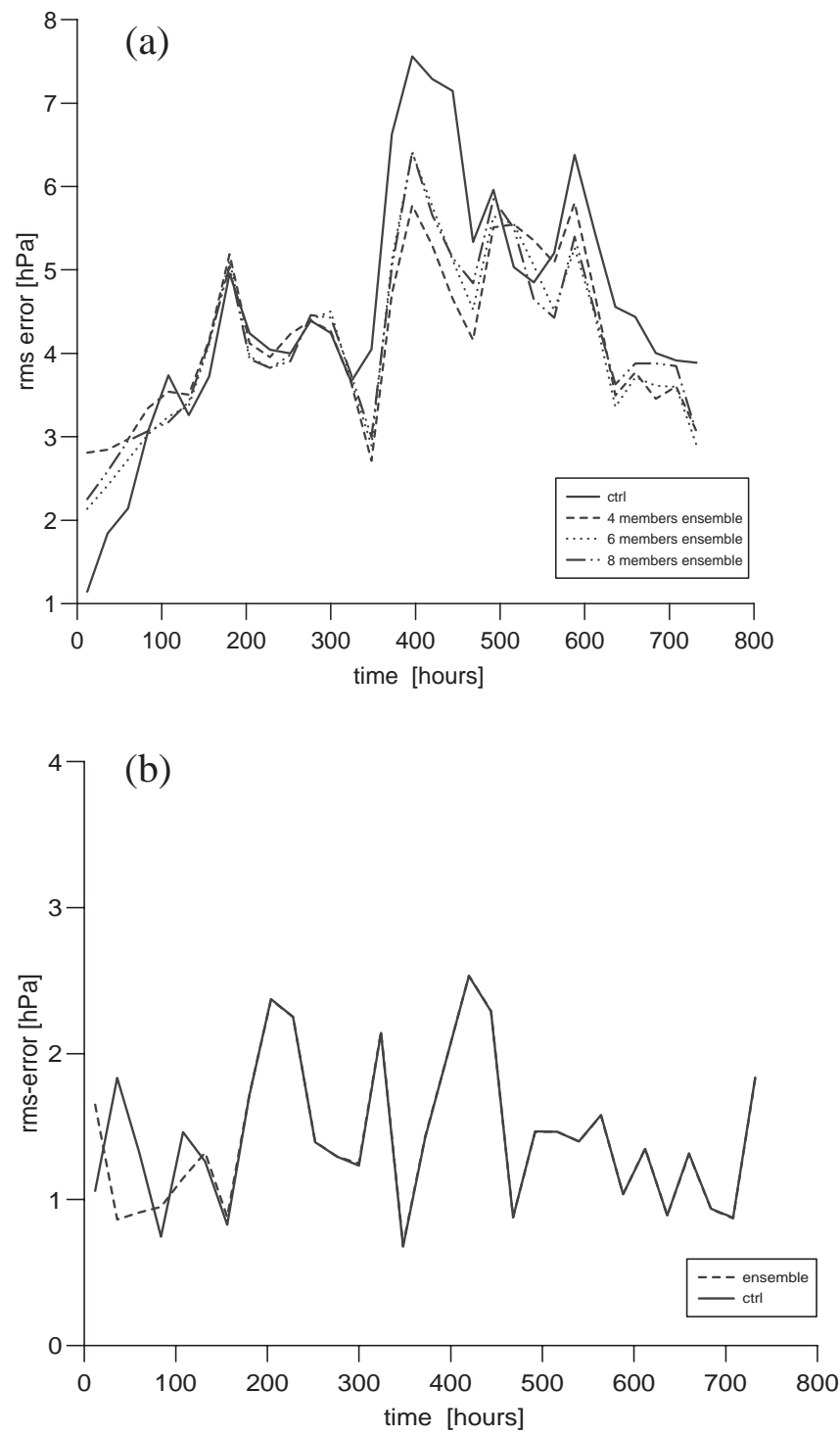

Fig. 12. Domain-averaged rms difference for the J uly 1990 mean sea level pressure. Bold line: control run (single month run for J uly 1990: run aw); dashed line: 4-member ensemble (runs aw to aw4); dotted line: 6-member ensemble (runs aw to aw6); dashed-dotted line: 8-member ensemble (runs aw to aw8). (a) Domain ARC and (b) domain AO 
(a)

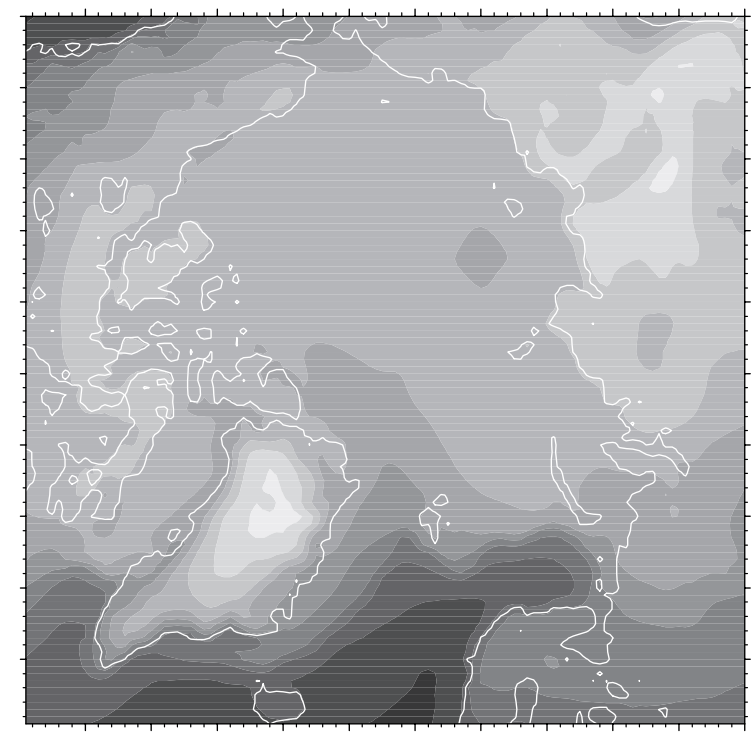

$\left[{ }^{\circ} \mathrm{C}\right]$

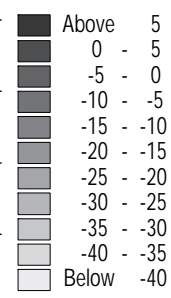

Fig. 13. Geographical distribution of monthly mean (a) lowest model level temperature from the run with $1 \mathrm{~m}$ sea ice thickness, (b) lowest model level temperature difference ' $1 \mathrm{~m}$ minus $4 \mathrm{~m}$ sea ice thickness' in $\mathrm{K}$ and (c) sea level pressure difference ' $1 \mathrm{~m}$ minus $4 \mathrm{~m}$ sea ice thickness' in hPa for J anuary 1990 (b)

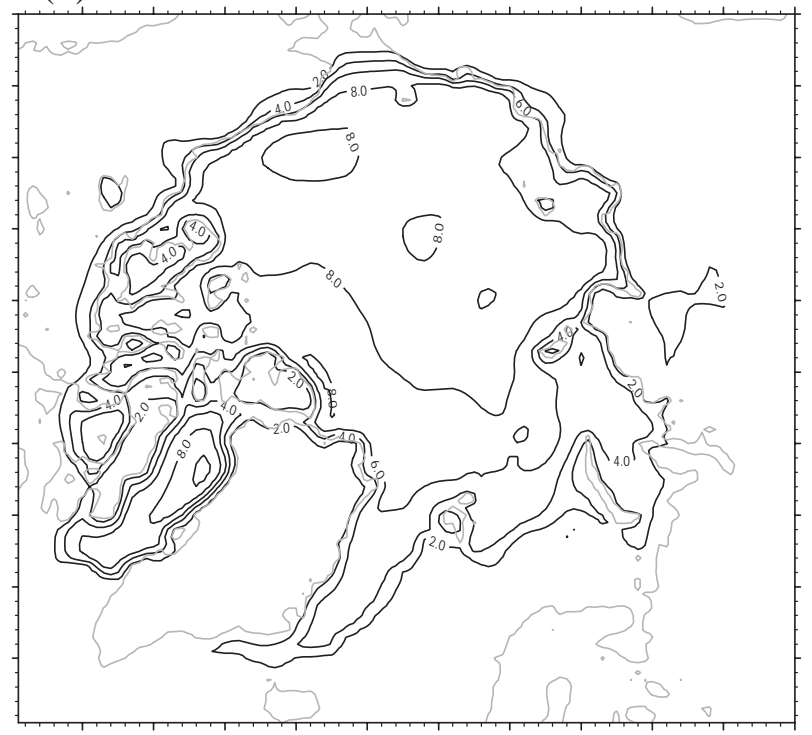

Acknowledgements. We are grateful to I. Hebestadt for programming assistance and preparing the figures. We would like to thank J. H. Christensen, W. Dorn, and H. Herzog for their insight and helpful discussions. We thank A. Weisheimer and D. Handorf for preparing the EOF calculations and discussions. We thank $\mathrm{H}$. von Storch for encouraging us to deal with this topic. We benefited very much from helpful comments by R. Laprise and 2 anonymous reviewers, which improved our manuscript. The HIRLAM system was developed by the HIRLAM project group, a cooperative project of the national weather services in Denmark, Finland, Iceland, Ireland, the Netherlands, Norway and Sweden. This is AWI contribution 1468. (c)



\section{LITERATURE CITED}

A begg C, Dethloff K, Rinke A, Romanov V (1997) Influence of planetary boundary layer parameterization on Arctic climate simulations. International Conference on Polar Processes and Global Climate, 3- 6 November 1997, Rosario Resort, Washington, DC. WMO, Geneva, p 1-3

Anthes RA (1986) The general question of predictability. In: Ray PS (ed) Mesoscale meteorology and forecasting, American M eteorological Society, Boston, p 636-655

Anthes RA, Kuo YH, Hsie EY, Low-Nam S, Bettge TW (1989) Estimation of episodic and climatological skill and uncertainty in regional numerical models. Q J R Meteorol Soc 
115:763-806

Bhaskaran B, J ones RG, M urphy J M, Noguer M (1996) Simulations of the Indian summer monsoon using a nested regional climate model: domain size experiments. Clim Dyn 12:573- 587

Christensen J H, Christensen OB, Lopez P, van Meijgaard E, Botzet M (1996) The HIRHAM 4 regional atmospheric climate model. DMI Scientific Report 96-4, Danish M eteorological Institute, Copenhagen

Christensen J H and 6 others (1997) Validation of present-day regional climate simulations over Europe: LAM simulations with observed boundary conditions. Clim Dyn 13: 489-506

Cress A, Majewski D, Podzun R, Renner V (1995) Simulation of European climate with a limited area model. Part I: Observed boundary conditions. Beitr Phys Atmos 68: 161-178

Dethloff K, Rinke A, Lehmann R, Christensen J H, Botzet $M$, Machenhauer B (1996) A regional climate model of the Arctic atmosphere. J Geophys Res 101:23401-23422

DKRZ (German Climate Computer Center) (1992) The ECHAM 3 atmospheric general circulation model. Tech. Report No. 6, DKRZ Hamburg

Flato G, Hibler WD (1995) Ridging and strength in modeling the thickness distribution of Arctic sea ice. J Geophys Res 100:18611-18626

Giorgi F (1990) Simulation of regional climate using a limited area model nested in a general circulation model. J Clim 3: 941-963

Giorgi F, Marinucci M R (1991) Validation of a regional atmospheric model over Europe: sensitivity of wintertime and summertime simulations to selected physics parameterization and lower boundary conditions. Q J R M eteorol Soc 117:1171-1206

Goyette S, Laprise J PR (1996) Numerical investigation with a physically based regional interpolator for off-line downscaling of GCM s: FIZR. J Clim 9:3464-3495

Hasselmann K (1976) Stochastic climate models. Part I: Theory. Tellus 28A:473-485

J ones RG, Murphy J M, Noguer M (1995) Simulation of climatic change over Europe using a nested regional-climate model. I. Assessment of control climate, including sensitivity to location of lateral boundaries. Q J R Meteorol Soc 121:1413-1449

Luethi D, Cress A, Davies HC, Frei C, Schaer C (1996) Interannual variability and regional simulations. Theor Appl Climatol 53:185-209

Lynch AH, Chapman WL, Walsh J E, Weller G (1995) Development of a regional climate model of the western Arctic. J Clim 8:155-1570

Lynch AH, Glueck MF, Chapman WL, Baily DA, Walsh JE (1997) Satellite observation and climate system model simulations of the St. Lawrence Island polynya. Tellus 49A:277-297

M achenhauer B, Windelband M, Botzet M, J ones RG, Deque

Editorial responsibility: Hans von Storch,

Geesthacht, Germany
M (1996) Validation of present-day regional climate simulations over Europe: nested LAM and variable resolution global model simulations with observed or mixed layer ocean boundary conditions. MPI Report No. 191, Max Planck Institute, Hamburg

Machenhauer B, and 7 others (1998) Validation and analysis of regional present-day climate and climate change simulations over Europe. MPI Report No. 275, Max Planck Institute, Hamburg

McGregor J L (1997) Regional climate modeling. Meteorol Atmos Phys 63:105-117

Molteni F, Buizza R, Palmer TN, Petroliagis T (1996) The ECMWF ensemble prediction system: methodology and validation. Q J R M eteorol Soc 122:73-119

Paegle J, Yang Q, Wang M (1997) Predictability in limited area and global models. M eteorol Atmos Phys 63:53-69

Pinto J O, Curry J A, Lynch AH (1997) Simulation of the spring transition over the Arctic ice pack. International Conference on Polar Processes and Global Climate, 3-6 N ovember 1997, Rosario Resort, Washington, DC. WM O, Geneva, p 188-190

Rabier F, Klinker E, Courtier P, Hollingsworth A (1996) Sensitivity of forecast errors to initial conditions. Q J R M eteorol Soc 122:121-150

Rinke A, Dethloff K, Christensen J H, Botzet M, M achenhauer $B$ (1997) Simulation and validation of Arctic radiation and clouds in a regional climate model. J Geophys Res 102: 29833-29847

Rinke A, Dethloff K, Christensen J H (1999) Arctic winter climate and its interannual variations simulated by a regional climate model. J Geophys Res 104:19027-19038

Roeckner E and 9 others (1996) The atmospheric general circulation model ECHAM 4: model description and simulation of present-day climate. MPI Report No. 218, Max Planck Institute, Hamburg

Sass BH, Christensen J H (1995) A simple framework for testing the quality of atmospheric limited area models. Mon Weather Rev 123:444-459

Seth A, Giorgi F (1998) The effects of domain choice on summer precipitation simulation and sensitivity in a regional climate model. J Clim 11:2698-2712

Toth Z, Kalnay E (1993) Ensemble forecasting at NMC: the generation of perturbations. Bull Am Meteorol Soc 74: 2317-2330

von Storch H (1995) Spatial patterns: EOFs and CCA. In: von Storch H, Navarra A (eds) Analysis of climate variability. Springer, Berlin, p 227-257

Vukicevic T, Errico R M (1990) The influence of artificial and physical factors upon predictability estimates using a complex limited-area model. Mon Weather Rev 118: $1460-1482$

Walsh J E, Lynch A, Chapman W, Musgrave D (1993) A regional model for studies of atmosphere-ice-ocean interaction in the western Arctic. Meteorol Atmos Phys 51: 179-194

Submitted: December 4, 1998; Accepted: September 15, 1999 Proofs received from author(s): J anuary 17, 2000 